\title{
Erkek Fertilitesi ve Riskli Yaşam Biçimi Davranışları
}

\author{
Male Fertility and Risky Lifestyle Behaviors
}

\author{
Nurdan DEMIRCI*, Dilek COŞKUNER POTUR**
}

İletişim/Correspondence: Dilek COŞKUNER POTUR Adres/Adress: Marmara Üniversitesi Sağlık Bilimleri Fakültesi Hemşirelik Bölümü Doğum ve Kadın Hastalıkları Hemşireliği Anabilim Dalı Tıbbiye Cad No 4034668 Haydarpaşa İstanbul Tel: $02163302070 / 1141$ Fax: 02164183773 E-mail: HYPERLINK “mailto:dilekcp@yahoo.com” dilekcp@yahoo.com

\section{$\ddot{O} Z$}

Endüstrileşme ve teknolojinin gelişmesi hayatı kolaylaştırdı̆̆ gibi insan sağlı̆̆ı üzerine olumsuz etkileri oldukça fazladır. Özellikle çevresel faktörlere oldukça duyarlı bir yapıya sahip olan üreme sistemi bu durumdan en çok etkilenen sistemdir. Son yıllarda yardımcı üreme teknikleri ile çocuk sahibi olmak için sağlık kurumlarına başvuran çift saylsı giderek artmaktadır. Infertilite nedenlerine bakıldĭ̆ında erkek faktörü, infertilite nedenlerinin yarısını oluşturmaktadır. Infertil çiftler değerlendirilirken erkek ve kadın iyi değerlendirilmeli ve yaşam biçimi davranışları (sigara alkol, madde bağımlılı̆̆l, beslenme), mesleği (çevresel maruziyet, stres), boş zamanları değerlendirme şekilleri (telefon, diz üstü bilgisayar kullanımı vb.) ya da sağlıklı yaşam biçimi olarak düşünülen bazı davranışları (sauna, jakuzi hamam vb.) sorgulanmalıdır. Bu makalede erkek fertilitesinde riskli olabilecek yaşam biçimi davranışları ve bu konuda yapılmış çalışmalar gözden geçirilmiştir.

Anahtar Kelimeler: Erkek fertilitesi, infertilite, sağllkll yaşam biçimi, stres.

\section{ABSTRACT}

The development of industrialization and technology makes life easier but it has many negative effects on health. The reproductive system, which is sensitive to environmental changes, is the most affected. In recent years, the usage of assisted reproductive techniques led to an increase in the number of couples who consults health institutions for assistance in conception. Factors pertaining to males comprise half of all fertility problems. Therefore, when a couple is subject to assessment regarding fertility, males and females should be evaluated thoroughly and their lifestyle behaviors (smoking, alcohol and substance abuse, exercise, nutrition), occupation (environmental exposure, stress), leisure time activities (cell phone and laptop use, etc.) or healthy lifestyle behaviors (sauna, jacuzzi, Turkish bath, etc.) should be investigated. This study reviews the lifestyle behaviors which can constitute a risk factor for male fertility and related research.

Key Words: Male fertility, infertility, healthy lifestyle, stress.

\footnotetext{
* Doç. Dr. Marmara Üniversitesi Sağllk Bilimleri Fakültesi Hemşirelik Bölümü, ** Dr. Marmara Üniversitesi Sağlk Bilimleri Fakültesi Hemşirelik Bölümü

Yazının gönderilme tarihi: 17.04.2013

Yazının basım için kabul tarihi: 06.01.2014
} 


\section{GİRIŞ}

Son 50 yıldır yapılan araştırmalarda semen kalitesinde düşüş eğilimi olması, gelecekte erkek fertilitesi ile ilgili endişelere neden olmuştur (Carlsen, Giwercman, Keiding ve Skakkeblek 1992; DeMouzon, Thonneau, Spira ve Multigener 1996; Mendiola ve ark. 2008; Merzenich, Zeeb ve Blettner 2010). Avustralya'da tüm infertil olgularının yarısı erkek faktörü olup genel nüfus içinde 20 erkekten birinin infertil olduğu belirlenmiştir (McLachlan ve DeKrester 2001).

Çin'de sağlıklı erkeklerle yapılan, büyük ölçekli bir çalışmada, \%38.9'unun sperm analizlerinin Dünya Sağlık Örgütü'nün kriterlerine uygun olmadığı belirlenmiş, erkek fertilitesi ile ilgili bu olumsuz değişime yaşam biçiminin etkisi olduğu ortaya atılmıştır (Li, Lin, Li ve Cao 2011). Özellikle Batı toplumlarında endüstrileşme sonrası bazı yaşam tarzının (obezite, yetersiz beslenme) (Homan, Davies ve Norman 2007), boş zamanı değerlendirme şeklinin (cep telefonu, diz üstü bilgisayar, sauna vb ) erkek üreme sağl1ğını olumsuz yönde etkilediği düşünülmektedir (Mendiola, Torres-Cantero ve Agarwal 2009; Mendiola ve ark. 2008; Pacey 2010).

Sağlıklı yaşam biçiminin amacı sadece herhangi bir hastalık ya da rahatsızlığı önlemeye yönelik olmayıp, bireyin genel sağlik ve iyilik durumunu iyileştirmektir. Nitekim fertilitede sağlıklı yaşam biçiminin geliştirilmesi, genel sağlık durumunun iyileştirilmesi, infertilitenin önlenmesi ve fertilite yeteneğinin ideal düzeye getirilmesinde önemli yere sahiptir (Güngör ve Beji 2009; Teskereci ve Öncel 2012).

Yaşam biçimi ile ilgili faktörlerin genel sağlık ve fertilite üzerine olan etkisi konusundaki kanttlar her geçen gün artmaktadır. İnfertilite ile ilgili yaşam biçimi davranışları, fertiliteyi olumsuz etkileyen değiştirilebilir alışkanlıklar, davranışlar ya da durumlardır (Teskereci ve Öncel 2012).

$\mathrm{Bu}$ makalenin amac1, günümüzde değişen yaşam biçimi davranışlarının artan erkek infertilitesi ile ilgili sorunlarda nasıl etkili oldukları hakkında bilgi sağla- maktır. Kraliyet Koleji Jinekolog ve Obstetrisyenler Birliği'nin (Royal College of Obstetricians and Gynaecologists - RCOG) 2004 yılında geliştirdiği ve 2012 yılında tekrar güncellediği "Doğurganlık: Fertilite Problemleri olan İnsanlar için Değerlendirme ve Tedavi Rehberi” doğrultusunda erkek fertilitesi üzerinde etkili olan riskli yaşam biçimi davranışları ile ilgili önerilerde bulunulmuştur (Royal College of Obstetricians and Gynaecologists Publications 2012).

\section{Erkek Fertilitesinde Riskli Olan Yaşam Biçimi Davranışları}

İnfertilite sorunu yaşayan çiftlerde ve yardımcı üreme tekniklerinin (YÜT) başarısında etkili olan faktörler hormonal stimülasyona cevap, sperm kalitesi, kaliteli embriyo sayısı ve yaşam biçimi davranışlarıdır. İnfertilite sorunun çözümünde ve YÜT başarısında olumlu etkileri olan yaşam biçimi davranışları ile ilgili infertil çiftin yapabilecekleri katkılar ile olumlu sonuçlar almak mümkündür. Erkeğin fertilitesi ile ilişkili en çok araştırılan ve öneriler sunulan yaşam biçimi davranışları, sigara içme, alkol, kafein, madde bağımlı̆̆ me, egzersiz, çevresel zararlı maddeler/ meslek, strestir (Revonta ve ark. 2010). Şekil 1'de yaşam şeklinin erkek üreme fonksiyonları üzerine etkileri özetlenmiştir.

\section{Sigara}

Sigara, fertilite ve yardımcı üreme teknikleri tedavisini en fazla etkileyen yaşam biçimidir. Sigara reprodüktif toksindir (Mostafa 2010; The Practice Committe of the American Society for Reproductive Medicine 2012; Zitzmann ve ark. 2003). Sigara içenlerde, içmeyenlere göre infertilite riski 1.6 kat daha fazladır. Günde $>20$ sigara içenlerde seminal mayide kadmiyum oranı artmıştır. Yaş, sigara içme süresi, seminal kadmiyum ile semen yoğunluğu arasında negatif korelasyon bulunmuştur (Mostafa 2010).

Öneri: Sigara içen erkekler, sigara içme ile semen kalitesinin düşmesi arasında bir ilişki (sigara içmenin erkek infertilitesine etkisi tam olarak bilinmese de) olduğu konusunda bilgilendirilmeli ve genel sağlıkları açısından sigarayı bırakmaları tavsiye edilmelidir 


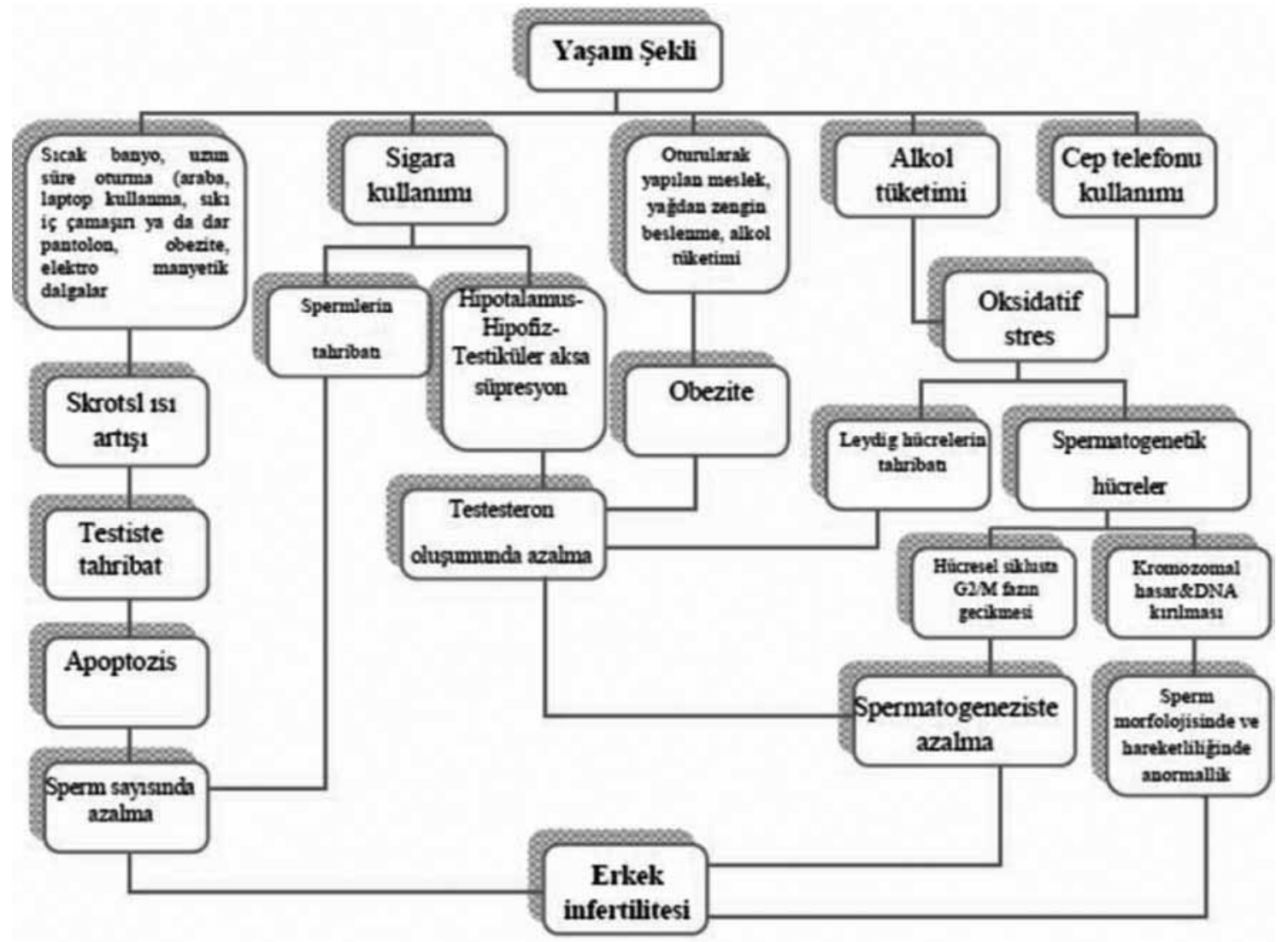

Şekil 1: Yaşam Şeklinin Erkek Üreme Fonksiyonları Üzerine Etkisi

Kaynak: Pramanic, P. (2012). Impact of adulthood lifestyle on male infertility: A critical review of the current literature. International Journal of Life Science \& Pharma research, 2(4): 51-61.

(Royal College of Obstetricians and Gynaecologists Publications 2012).

\section{Alkol}

Alkol bilinen bir teratojen olmakla birlikte tüketilme miktarı ile infertilite riski ile ilişkisi net değildir. Aş1r1 alkol kullanımı, testis atrofisine, impotansa, libidonun azalmasına ve sperm sayısının azalmasına sebep olur (Anderson, Nisenblat ve Norman 2010; Pramanic 2012 ).

Öneri: Günde 3-4 kadehten fazla alkol almamaları belirtilmelidir. Aşırı alkol tüketiminin semen kalitesine zararlı olduğu konusunda erkekler bilgilendirilmelidir (Royal College of Obstetricians and Gynaecologists Publications 2012).

\section{Kafein}

Kafein tüketiminin fertilite üzerine etkisinin tüketilen miktara bağlı olduğu belirtilmektedir. Kafein alımı ile kötü (bozuk) semen parametresi arasında bir ilişki olduğuna ait kanıt bulunmamaktadır (Klonoff-Cofen 2005).

Öneri: Kahve ve sigara birlikte kullanıldığında, sperm motiltesi azalmakta ve ölü sperm oranı artmaktadır. Gebelik planlayan çiftlerin kafein tüketimini günde 2 fincanla sınırlamaları tavsiye edilmiştir (KlonoffCofen 2005).

\section{Keyif Verici İlaç Kullanımı (Uyuşturucu Maddeler)}

Esrar, leyding hücrelerini ve sperm hareketliliğini, akrozom reaksiyonunu, testesteron üretimini azaltır, spermatogenezisi negatif etkiler. Anabolik steroid ve 
kokain kullanımı semen kalitesini olumsuz etkileyebilir (Anderson ve ark. 2010).

Öneri: Keyif verici ilaçların kullanılması erkek fertilitesine zarar verir ve bu sebepten dolayı fertilitesinden endişeli olan kişilerden kullandıkları ilaçlar konusunda ayrıntılı bir anamnez alınmalı ve keyif verici ilaç kullanımının fertilite üzerindeki olumsuz etkilerine yönelik bilgi verilmeli kullanım bağımlılık düzeyinde ise terapi önerilmelidir (Royal College of Obstetricians and Gynaecologists Publications 2012).

\section{Beden Kitle İndeksi}

Yağ dokusundaki artış, testesteronun östrojene dönüşümü arttırır ve sonuçta kanda testesteron düzeyi aza11r. Sperm sayısı \%20 azalır, sperm kalitesi düşer, testis bölgesindeki yağ oranı artar, bölgedeki 1sıyı yüksek tutar ve sperm üretim ve kalitesini düşürür. Yapılan bir çok çalışma beden kitle indeksi $30 \mathrm{~kg} / \mathrm{m}^{2}$ ve daha yüksek olan erkeklerin sperm kalitesi üzerine önemli olumsuz etkilerinin olduğu belirlenmiştir (Hammiche ve ark. 2012; Hammoud ve ark. 2008; Kort ve ark. 2006; Magnusdottir, Thorsteinsson, Thorsteinsdottir, Heimisdottir ve Olafsdottir 2011; Pramanic 2012; Sallmen, Sandler, Hoppin, Blair ve Baird 2006). Erkekte BKI $<20 \mathrm{~kg} / \mathrm{m}^{2}$ ile $>25 \mathrm{~kg} / \mathrm{m}^{2}$ arasında olduğunda sperm kalitesini azaldığ Davies ve Norman 2007; Jensen ve ark. 2004).

Öneri: BKİ 29'un üzerinde ve $<20 \mathrm{~kg} / \mathrm{m}^{2}$ ile $>25 \mathrm{~kg}$ / $\mathrm{m}^{2}$ arasında olan erkeklerde fertilite şanslarının azaldığı konusunda bilgilendirilmelidir (Royal College of Obstetricians and Gynaecologists Publications 2012).

\section{Beslenme}

Çeşitli araştırmalarda çinko eksikliğinin spermatogenezi olumsuz etkilediğine yönelik bulgular olmasına rağmen, kesin patofizyolojisi açıklığa kavuşmamıştır. Fertil ve inferftil erkekler kıyaslandığında az meyve tüketiminin oligospermiye neden olduğu belirlenmiştir (Wong ve ark. 2000).

Öneri: Beslenmenin erkek fertilitesi üzerine etkileri konusunda daha fazla çalışma yapılmasına gereksinim vardır (Wong ve ark. 2000).

\section{Meslek ve Çevresel Zararı Maddeler}

Meslekler yaşam tarzımızda önemli ölçüde etkilemektedir. Bazı meslekler maruziyete neden olurken bazı mesleklerde uzun süre oturarak (banka, bilgisayar programcılığ $v$ vb.) hareket kisitlığına neden olmaktadir. $\mathrm{Bu}$ durum skrotum çevresindeki havanın sirkülasyonunu engeller ilaveten sıkı iç çamaşırı ya da dar pantolonlar tercih ediliyorsa 1sı artışına neden olarak sperm sayısını azaltır ve anormal sperm üretimine neden olur (Pramanic 2012).

Günümüzde işyerlerinde 104.000 den fazla kimyasal ve fiziksel ajanın kullanıldığı saptanmış olup, bunların \% 95'inin üreme üzerine etkileri belirlenememiştir (Demirci, Yiğit ve Doğan 2009). Çevre kirliliğine yol açan organik civa, pestisitler (tarım ilacı), kurşun, kaynak, organik solventler, radyasyon ve yapıştırıcı gibi maddelerin üreme ve fetal gelişim üzerine olumsuz etkileri olduğu belirlenmiştir (Anderson ve ark. 2010; Homan ve ark. 2007). Glikol ethere maruz kalma sperm sayısında azalmaya, (Cherry ve ark. 2008), mesleki kimyasallara maruz kalma ise oligoastenospermiye neden olmaktadır (Mendiola ve ark. 2008). Elektrik ve manyetik alanın etkileri de tartışmalıdır (Homan ve ark. 2007). Pestisite maruz kalma sperm sayısını \%40 azaltmaktadır (Olivia, Spira ve Multigner 2001). Fitalat (boya sanayinde kullanılan) maruziyeti ve infertilite ilişkili bulunmuştur (Duty ve ark. 2003; Güngör ve Beji 2009).

Öneri: Tehlikeli etkenlere maruz kalan bazı meslekler, erkek fertilite şansını düşürebilir. Bu nedenle fertilitesi konusunda endişeli olan kişilerin meslekleri özel olarak sorgulanmalıdır (Royal College of Obstetricians and Gynaecologists Publications 2012). Eğer mesleki maruziyetleri bulunuyorsa, fertilite şanslar1$\mathrm{n} 1$ arttırabilmek amacı ile maruziyetleri kısıtlanmas1na yönelik bireyin ve iş yerinin koşulları doğrultusunda mesleki düzenlemeler yapılmalıdır.

Erkekler skrotal sıcaklığın yükselmesi ile semen kalitesinin düşmesi arasında bir ilişki olduğu konusunda bilgilendirilmelidir. Mesleğini uzun süre oturarak yapan erkeklere işlerine periyodik olarak ara vererek 
dolaşarak skrotal sıcaklık artışını engellemeleri konusunda bilgi verilmelidir.

\section{Boş Zamanı Değerlendirme Şekli}

Bazı gözlemsel çalışmalarda cep telefonu kullanımının sperm sayısı hareketliliği, canlı kalma süresi üzerine negatif etkileri olduğu belirlenmiştir (Fejes ve ark. 2005; Mendiola ve ark. 2009; Pramanic 2012).

Sheynkin, Jung, Yoo, Schulsinger ve Komaroff (2005)'un yaptıkları çalışmada diz üstü bilgisayar kullanımını skrotal 1sı artışına neden olduğunu belirtilmişlerdir. Sauna, jakuzi gibi $38^{\circ} \mathrm{C}$ 'nin üzerinde sicak ortamlarda 30 dakikadan fazla durmak skrotal 1s1 art1\$̧1 ve anormal sperm üretimine neden olmaktadır (Pramanic 2012).

Öneri: Fertilite problemi yaşayan bireylere mesleği gereği ya da boş zamanları değerlendirmede dizüstü bilgisayar kullanım süresi ve oturma pozisyonu sorgulanmalıdır. Diz üstü bilgisayar kullanırken skrotal 1s1 artışına neden olduğu için bacakların kapalı olmamasına dikkat etmesi gerektiği söylenmeli ve yarım saat aralıkla ayağa kalkıp dolaşması, sauna jakuzi gibi ortamlarda 30 dakikadan fazla kalınmaması, cep telefonu kullanımının gün içinde 60 dakikayı geçmemesi konularında bilgi verilmelidir.

\section{Stres ve erkek infertilitesi}

İnfertilite ile psikolojik stres arasındaki ilişki karmaş1ktır. Stres infertilite nedeni iken, infertil olmakta strese neden olabilir. Psikolojik stres, sperm yoğunluğunun hareketli ve normal sperm oranının azalmasına, anormal sperm üretiminin artmasına neden olur (Şahin, Bilgiç ve Demirgöz 2009; Teskereci ve Öncel 2012).

İnfertil erkekler impotans, cinsel ilişkide performans azalması, anksiyete gibi stres faktörleri ile de doğal gebelik elde etmede güçlük yaşayabilirler (Anderson ve ark. 2010).

Öneriler: Fertilite sorunu yaşayan çiftler stres nedeniyle eş ilişkilerinin libido azalması dolayısıyla cin- sel ilişki sıklığının azalması nedeniyle etkilenebileceği konusunda bilgilendirilmelidir. Fertilite sorunu yaşayan kişiler tanı ve tedavi işlemleri sırasında psikolojik stres yaşayabilecekleri için danışmanlık almalar1 önerilmelidir (Royal College of Obstetricians and Gynaecologists Publications 2012).

\section{Oksidatif Stres}

Çeşitli çevresel faktörler ve yaşam biçimi (sigara, alkol, obezite, çevre kirliliği vb) antioksidan aktivitesinin azalmasına, serbest radikallerin aşırı üretilmesine neden olarak oksidatif stres yolu ile erkek üreme sistemini etkilemektedir. Oksidatif stres hücre zarı, doku, DNA hasarına neden olur ve hücre bölünmesini engeller. Erkeklerde sperm sayı ve hareketlerinde azalma, anormal sperm sayısında artışa neden olduğu düşünülmektedir (Anderson ve ark. 2010; Tremellen 2008).

Öneri: İnsanlarda üreme fonksiyonu üzerine antioksidan etkinliğini değerlendiren çalışmalar kesin kanıt sunmamakla birlikte, esansiyel yağ asitleri, Selenyum, Çinko, Asetil-sistein, E ve C Vitamini, Beta Karoten ve bunların kombinasyonlarının erkeklerde, oksidatif stresi ve spermlerde DNA hasarını azalttığı, sperm kalitesinde iyileşme olduğu belirlenmiştir (Anderson ve ark. 2010; Tremellen 2008).

Sonuç olarak; erkek fertilitesini olumsuz yönde etkileyen birçok değiştirilebilinir ya da önlem alınabilir davranışsal ve çevresel faktör bulunmaktadır. Hemşireler bireylere yaşamın her dönemlerinde bakım verme, danışmanlık yapma, eğitim verme gibi rolleri ile sorun çözümünde yardımcı olabilecek önemli fırsatlara sahiptirler. Koruyucu sağlık hizmetlerinde çal1şan hemşireler, sağlıklı yaşam biçimi davranışları geliştirilmesi konusunda yol göstererek, riskli davranışların değiştirilmesi için danışmanlık vererek, bireylerin gelecekteki fertilite yeteneklerinin bozulmasını önleyebilirler. İnfertilite hemşireleri, fertilite sorunu yaşayan ya da YÜT gibi uzun süreli ve mali aç1dan oldukça pahalı olan tedavi şekli ile çocuk sahibi olmak için başvuran çiftlerden anamnez alırken yaşam biçimi davranışlarını tek tek sorgulamalıdır 
ERKEK FERTILLITESİ RISKLII YAŞAM BICÇIMİ DAVRANIŞLARI DEĞERLENDİRME FORMU

\begin{tabular}{|c|c|c|c|c|}
\hline YAŞAM BİÇIMII DAVRANIŞLARI & $\begin{array}{l}\text { Bireyin } \\
\text { Durumu }\end{array}$ & $\begin{array}{c}\text { Risk } \\
\text { Var }\end{array}$ & $\begin{array}{c}\text { Risk } \\
\text { Yok }\end{array}$ & $\begin{array}{l}\text { Öneri / } \\
\text { Yorum }\end{array}$ \\
\hline \multicolumn{5}{|l|}{ Sigara } \\
\hline \multicolumn{5}{|l|}{ Günlük kullanımı $>20$ 'den fazla } \\
\hline \multicolumn{5}{|l|}{ Alkol } \\
\hline \multicolumn{5}{|l|}{ Günde 3-4 kadehten fazla } \\
\hline \multicolumn{5}{|l|}{ Kafein tüketimi } \\
\hline \multicolumn{5}{|l|}{ Günde 2 fincandan fazla } \\
\hline \multicolumn{5}{|l|}{ Keyif verici ilaç kullanımı } \\
\hline \multicolumn{5}{|l|}{ Beden kitle indeksi } \\
\hline \multicolumn{5}{|l|}{$<20 \mathrm{~kg} / \mathrm{m}^{2}$} \\
\hline \multicolumn{5}{|l|}{$>25 \mathrm{~kg} / \mathrm{m}^{2}$} \\
\hline \multicolumn{5}{|l|}{ Mesleki maruziyet } \\
\hline \multicolumn{5}{|l|}{ Kimyasal (Boya sanayi, tarım ilaçları vb) } \\
\hline \multicolumn{5}{|l|}{ Fiziksel (Elektromanyetik dalgalar, 1sı) } \\
\hline \multicolumn{5}{|l|}{ Skrotal ısı artışına maruziyet } \\
\hline \multicolumn{5}{|l|}{ Sauna/ jakuzi > 30 dakika } \\
\hline \multicolumn{5}{|l|}{ Uzun süre oturma } \\
\hline \multicolumn{5}{|l|}{ S1k1 iç çamaşırı/dar pantolon giyme } \\
\hline \multicolumn{5}{|l|}{ Boş zamanı değerlendirme } \\
\hline \multicolumn{5}{|l|}{ Diz üstü bilgisayar kullanımı $>30$ dakika } \\
\hline Cep telefonu kullanımı günde $>1$ saat & & & & \\
\hline
\end{tabular}

Şekil 2. Erkek Fertilitesi Riskli Yaşam Biçimi Davranışları Değerlendirme Formu

(yazarlar tarafından örnek olarak geliştirilen "Erkek Fertilitesi Riskli Yaşam Biçimi Davranışları Değerlendirme Formu" ile Şekil 2). İnfertilite hemşiresi, erkek fertilitesi üzerine etkili olan yaşam tarzları konusunda çiftlere danışmanlık vermeli, konu ile ilgili güncel literatürü izlemelidir. Özellikle açıklanmayan infertilite ve erkek faktörlü infertilitede eğer çift için zaman problemi yoksa riskli yaşam biçimi davranışları varsa öncelikli onların değiştirilmesi için tedavi stratejileri geliştirilmeli, bireylere sağlıklı yaşam biçimi davranışları konusunda bireysel bakım planları ile yardımcı olunmalıdır.

\section{KAYNAKLAR}

Anderson, K., Nisenblat, V., Norman, R. (2010). Lifestyle factors in people seeking infertility treatment - A review. Australian and New Zealand Journal of Obstetrics and Gynaecology, 50(1): 8-20.
Carlsen, E., Giwercman, A., Keiding, N., Skakkeblek, N. E. (1992). Evidence for decreasing quality of semen during past 50 years. BMJ, 305(6854): 609-613.

Cerry, N. ve ark. (2008). Occupation and male infertility: Glycol ethers and other exposures. Occup Environ Med., 65(10): 708-714.

De Mouzon, J., Thonneau, P., Spira, A., Multigner, L. (1996). Declining sperm count: Semen quality has declined among men born in France since 1950. BMJ, 313(7048): 43.

Demirci, N., Yiğit, F., Doğan, D. (2009). İnfertilite hemşireliğinde kanıta dayalı uygulamalar. Beji, N. K. (Ed.). Inferilite Hemşireliği. Acar Basım, İstanbul, 227-241.

Duty, S. M. ve ark. (2003). Phthalate exposure and human semen parameters. Epidemiology, 14(3): 269-277.

Royal College of Obstetricians and Gynaecologists Publications (2012). Fertility: Assessment and treatment for people with fertility problems (update), http://www.nice.org.uk/nicemedia/ live/12157/59278/59278.pdf. (05.10.2012). 
Fejes, I. ve ark. (2005). Is there a relationship between cell phone use and semen quality? Arch Androl., 51: 385-93.

Güngör, İ., Beji, N. K. (2009). İnfertil çiftlerde sağlıklı yaşam biçimi davranışları geliştirme ve hemşirenin rolü. Beji, N. K. (Ed.). In ferilite Hemşireliği. Acar Basım, İstanbul, 163-176.

Hammiche, F. ve ark. (2012). Body mass index and central adiposity are associated with sperm quality in men of subfertile couples. Hum Reprod, 27(8): 2365-2372.

Hammoud, A. O. ve ark. (2008). Male obesity and alteration in sperm parameters. Fertility and Sterility, 90(6): 2222-2225.

Homan, G. F., Davies, M., Norman, R. (2007). The impact of lifestyle factors on reproductive performance in the general population and those undergoing infertility treatment: A review. Hum Reprod Update, 13(3): 209-223.

Jensen, T. K. ve ark. (2004). Body mass index in relation to semen quality and reproductive hormones among 1558 Danish men. Fertil Steril, 82(4): 863-870.

Klonoff-Cohen, H. (2005). Female and male lifestyle habits and IVF: What is known and unknown. Human Reproduction Update, 11(2): 179-203.

Kort, H. I. ve ark. (2006). Impact of body mass index values on sperm quantity and quality. $J$ Androl, 27(3): 450-452.

Li, Y., Lin, H., Li, Y., Cao, J. (2011). Association between sociopstcho-behavioral factors and male semen quality: Systematic review and meta-analyses. Fertil Steril, 95(1): 116-123.

Magnusdottir, E. V., Thorsteinsson, T., Thorsteinsdottir, S., Heimisdottir, S., Olafsdottir, K. (2004). Obesity and increased risk for oligozoospermia and azoospermia. Human Reproduction, 20(1): 208-215.

McLachlan, R. I., DeKrester, D. M. (2001). Male infertility: The case for continued research. Med J Aust., 174(5): 116-117.

Mendioal, J. ve ark. (2008). Exposure to environmental toxins in males seeking infertility treatment: A case-controlled study. Reprod Biomed Online, 16: 842-850.

Mendiola, J., Torres-Cantero, A. M., Agarwal, A. (2009). Lifestyle factors and male infertility: An evidence-based review. Arch of Med $\mathrm{Sci}$, 5(1A): S3-S12.
Merzenich, H., Zeeb, H., Blettner, M. (2010) Decreasing sperm quality: A global problem? BMJ Public Health, 10: 24.

Mostafa, T. (2010). Cigarette smoking and male infertility. Journal of Advanced Research, 1(3): 179-186.

Olivia, A., Spira, A., Multigner, L. (2001). Contribution of environmental factors to the risk of male infertility. Hum Reprod, 16(8): 1768-1776.

Pacey, A. A. (2010). Environmental and lifestyle factors associated with sperm DNA damage. Hum Fertil, 13(4): 189-193.

Pramanic, P. (2012). Impact of adulthood lifestyle on male infertility: A critical review of the current literature. International Journal of Life Science \& Pharma research, 2(4): 51-61.

Revonta, M. ve ark. (2010). Health and life style among infertile men and women. Sexual \& Reproductive Healthcare, 1(3): 91-98.

Sallmen, M., Sandler, D. P. Hoppin, J. A., Blair, A., Baird, D. D. (2006). Reduced fertility among overweight and obese men. Epidemiology, 17(5): 520-523.

Sheynkin, Y., Jung, M., Yoo, P., Schulsinger, D., Komaroff, E. (2005). Increase in scrotal temperature in laptop computer users. Hum Reprod, 20(2): 452-455.

Şahin, N. H, Bilgiç, D., Demirgöz, M. (2009). Doğurganlığ1 etkileyen faktörler. Beji, N. K. (Ed.). Inferilite Hemşireliği. Acar Basim, İstanbul, 11-32.

Teskereci, G., Öncel, S. (2013). The effect of the life style on quality of life of couples receiving infertility treatment. Journal of Sex \& Marital Therapy, 39(6): 476-492.

The Practice Committe of the American Society for Reproductive Medicine (2012). Smoking and infertility: A committee opinion, http://www.asrm.org/Smoking_and_infertility/ (28.01.2013).

Tremellen, K. (2008). Oxidative stress and male infertility - A clinical perspective. Hum Reprod Update, 14(3): 243-258.

Wong, W. Y., Thomas, C. M., Merkus, J. M., Zielhuis, G. A., Steegers-Theunissen, R. P. (2000). Male factor subfertility: Possible causes and the impact of nutritional factors. Fertil Steril, 73(7): 435-442.

Zitzmann, M. ve ark. (2003). Male smokers have a decreased success rate for in vitro fertilization and intracytoplasmic sperm injection. Fertil Steril, 79(3): 1550-1554. 